\title{
ДЕТЕКЦИЯ ХРОМОСОМНЫХ ПЕРЕСТРОЕК В КОРОТКОМ ПЛЕЧЕ 4-Й И 12-Й ХРОМОСОМ КАК ПРИМЕР ПОЛНОГЕНОМНОГО ПОДХОДА ПРИ ПРОВЕДЕНИИ НЕИНВАЗИВНОГО ДНК-СКРИНИНГА
}

А. Ю. Гольцов $џ$, И. С. Мукосей, Т. О. Кочеткова, Е. Шубина, М. В. Кузнецова, О. К. Ступко, И. Ю. Барков, Д. В. Ребриков, Д. Ю. Тросимов

Национальный медицинский исследовательский центр акушерства, гинекологии и перинатологии имени В. И. Кулакова, Москва, Россия

Своевременное обнаружение анеуплоидий плода очень важно в клинической практике. В настоящее время идет активное развитие аналитических методов с применением высокопроизводительного секвенирования. Благодаря неинвазивному пренатальному ДНК-скринингу (НИПС) достоверные результаты можно получать на сроке 9-11 недель. Описан клинический случай применения НИПС и дальнейшей верификации полученных результатов. С помощью методов высокопроизводительного секвенирования, микроматричного анализа амниотической жидкости и цитогенетического кариотипирования у плода обнаружен высокий риск хромосомных перестроек в коротком плече 4-й и 12-й хромосом. Результаты были подтверждены с помощью молекулярного кариотипирования. Проверка родителей позволила выявить у матери сбалансированные хромосомные перестройки в 4-й и 12-й хромосомах. Данный случай демонстрирует преимущества полногеномного подхода перед таргетным при проведении НИПС.

Ключевые слова: анеуплоидии, неинвазивный пренатальный ДНК-скрининг, синдром, инвазивная диагностика, комбинированный скрининг

Информация о вкладе авторов: А. Ю. Гольцов, И. С. Мукосей - неинвазивный пренатальный ДНК-скрининг; Е. Шубина, Т. О. Кочеткова - анализ данных; М. В. Кузнецова - микроматричный анализ; О. К. Ступко - цитогенетическое кариотипирование; И. Ю. Барков - медико-генетическое консультирование; Д. Ю. Трофимов, Д. В. Ребриков - руководство.

Соблюдение этических стандартов: исследование было одобрено этическим комитетом ФГБУ «НЦАГиП имени В. И. Кулакова» (протокол № 2015/13).

$\triangle$ Для корреспонденции: Андрей Юрьевич Гольцов

ул. Академика Опарина д. 4, г. Москва, 117997; andrey.goltsov@gmail.com

Статья получена: 24.05.2019 Статья принята к печати: 08.06.2019 Опубликована онлайн: 15.06.2019

DOI: $10.24075 /$ vrgmu.2019.040

\section{DETECTION OF CHROMOSOMAL REARRANGEMENTS IN THE SHORT ARMS OF CHROMOSOMES 4 AND 12 AS AN EXAMPLE OF A WHOLE-GENOME APPROACH TO NONINVASIVE PRENATAL TESTING}

Goltsov AYu凶, Mukosey IS, Kochetkova TO, Shubina J, Kuznetsova MV, Stupko OK, Barkov IYu, Rebrikov DV, Trofimov DYu

Kulakov National Medical Research Center for Obstetrics, Gynecology and Perinatology, Moscow, Russia

Timely detection of fetal aneuploidy is an important aspect of clinical practice. At present, analytical techniques involving high-throughput sequencing are on the rise. Noninvasive prenatal testing (NIPT) ensures reliable results as early as week 9-11 into pregnancy. This article describes a clinical case of NIPT application and further verification of its results. Using next-generation sequencing, the microarray analysis of cell-free DNA in the amniotic fluid and the cytogenetic analysis of fetal chromosomes, a high risk of chromosomal rearrangements was detected in the short arms of chromosomes 4 and 12. This prediction was verified by molecular karyotyping conducted in both parents. The mother was found to be a balanced carrier of translocations between chromosomes 4 and 12. This case demonstrates the advantages of a whole-genome approach to NIPT over targeted-based.

Keywords: aneuploidy, noninvasive prenatal testing, syndrome, invasive diagnostic test, combined screening

Author contribution: Goltsov AYu, Mukosey IS — noninvasive prenatal screening; Shubina J, Kochetkova TO — data analysis; Kuznetsova MV — microarray analysis; Stupko OK — cytogenetic chromosome analysis; Barkov IYu — genetic counseling; Trofimov DYu, Rebrikov DV — study supervision.

Compliance with ethical standards: the study was approved by the Ethics Committee of Kulakov National Medical Research Center for Obstetrics, Gynecology and Perinatology (Protocol № 2015/13).

$\square$ Correspondence should be addressed: Andrey Yu. Goltsov

Akademika Oparina 4, Moscow, 117997; andrey.goltsov@gmail.com

Received: 24.05.2019 Accepted: 08.06.2019 Published online: 15.06.2019

DOI: $10.24075 /$ brsmu.2019.040

Хромосомные анеуплоидии (ХА) оказываются частой причиной перинатальной смертности и нарушений развития плода. Их обнаруживают примерно в каждом третьем случае неразвивающейся беременности и выкидыша. У новорожденных ХА встречаются с частотой до $1: 300$. Среди наиболее часто обнаруживаемых анеуплоидий можно назвать трисомии по 21-й, 18-й и 13-й хромосомам [1], а также анеуплоидии по половым хромосомам. Одним из факторов риска наличия ХА является возраст матери.

Для своевременного обнаружения ХА плода в России в настоящее время проводят комбинированный скрининг, основанный на результатах УЗИ и биохимических показателях в 1-м триместре беременности [2]. Скрининг имеет ограничение по чувствительности и специфичности, так как изменения биохимических показателей зависят не только от хромосомного статуса плода, но и от гормонального фона беременной женщины и других факторов. При высоком риске по биохимическим показателям формируют группу, в которой можно проводить дополнительные исследования для более точной детекции хромосомных нарушений. Подтверждение наличия ХА происходит примерно у 13-15\% пациенток группы. Подтверждающую диагностику проводят инвазивными методами (биопсия хориона, амниоцентез или кордоцентез), что может быть причиной потери плода в 0,5-2\% случаев и противопоказано женщинам с повышенным риском прерывания беременности. В таких случаях и при сроке беременности не более 18-19 недель возможно определение наличия ХА плода по крови матери методом неинвазивного пренатального ДНК-скрининга (НИПС) [3]. Данная процедура не имеет противопоказаний для женщин с риском прерывания и возможна для 
проведения с 9-10-й недели беременности. В настоящее время существует много разновидностей НИПС. Различие между ними состоит в числе исследуемых хромосом. Едиными мишенями для большинства таких тестов служат хромосомы 13, 18 и 21 [4, 5]. Остальные хромосомы не всегда анализируют (тест Prenetix, панель Panorama) даже при полногеномном исследовании. Кроме того, существует анализ только по трисомии 21 (синдром Дауна), который также называют НИПС, но при этом отмечают, что данное исследование проводят только по 21-й хромосоме.

\section{Описание клинического случая}

Пациентка П., 30 лет. ИМТ = 17,6 кг/м². Имеет ребенка девочка 3 года, ДВС-синдром, гипертензионногидроцефальный синдром. Данная беременность третья, самопроизвольная. Результаты комбинированного скрининга 1-го триместра: ультразвуковые маркеры хромосомных аномалий и врожденные пороки развития не выявлены. ТВП = 1,3 мм. Кости носа определяются.

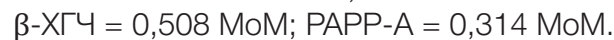

По результатам скрининга 1-го триместра установлены следующие риски:

риск трисомии 21- 1: 10084 (при изначальном базовом риске 1 : 585);

риск трисомии 18-1 : 1073 (при базовом риске 1 : 1396); риск трисомии 13-1: 1372 (при базовом риске $1:$ 4389).

Образец крови на НИПС был получен на сроке 13 недель 4 дня. Полногеномное секвенирование приготовленной из внеклеточной ДНК-библиотеки проводили с использованием прибора Ion S5XL (ThermoFisher Scientific; США), данные анализировали по ранее описанному протоколу [6], включая картирование полученных в результате секвенирования ридов на ресеренсный геном с проведением ГЦ-коррекции и подсчетом уникальных картированных ридов. Анализ риска ХА проводили с использованием программного обеспечения собственной разработки [7].

В результате анализа были сделаны следующие выводы. При количестве ридов полногеномной библиотеки 7,5 млн генетический пол плода - мужской, доля плодовой ДНК по Ү-хромосоме - 16\%. По хромосомам 13, 18, 21 анеуплоидий выявлено не было. Были обнаружены высокий риск делеции по короткому плечу 4-й хромосомы (включает регионы р16-р14), размер примерно 35 Мб (рис. 1A), а также дупликации по короткому плечу 12-й хромосомы (включает регионы p13.3-p12.1), размер

\section{A}

Хромосома 4

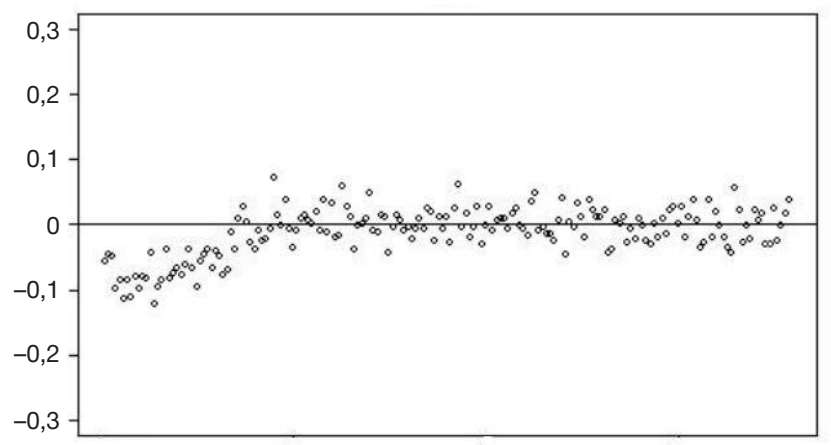

примерно 25 Мб (рис. 1Б). Полученные данные требуют подтверждения инвазивными методами [8, 9].

Для проверки полученных на НИПС данных [10] было назначено проведение микроматричного анализа амниотической жидкости с использованием микрочипов CytoScan Optima Array (Affimetrics; США). Забор амниотической жидкости проводили на сроке 16 недель.

Результаты пренатальной диагностики по амниотической жидкости представлены на рис. 2 и 3.

В ходе исследования установлен следующий молекулярный кариотип плода:

arr[hg19] 4p16.3(68,345-35,195,686)x1 - делеция короткого плеча 4-й хромосомы размером 35 млн п.н. Данная делеция соответствует синдрому ВольфаХиршхорна (Wolf-Hirschhorn syndrome OMIM 194190);

arr[hg19] 12p13.33p11.22(173,786-28,183,286)x3 дупликация короткого плеча 12-й хромосомы размером 28 млн п.н. Дупликация в данном регионе описана как синдром Паллистера-Киллиана, называемая также тетрасомией 12p (Pallister-Killian syndrome OMIM 601803).

По результатам молекулярного кариотипирования было рекомендовано прервать беременность. Беременность была прервана на сроке 18 недель.

\section{Обсуждение клинического случая}

В связи с тем что у плода обнаружены патогенные хромосомные перестройки, было рекомендовано провести кариотипирование родителей. Кариотипирование матери выявило сбалансированную транслокацию с вовлечением 4-й и 12-й хромосом, которая и была причиной появления нарушений у плода (рис. 4).

В ходе проведенных анализов редкие хромосомные нарушения были обнаружены благодаря тому, что при НИПС был использован полногеномный метод исследования. В настоящее время существует несколько видов НИПС. Некоторые из них основаны либо на таргетном сиквенсе 13-й, 18-й и 21-й хромосом, либо на выборочном анализе только определенных хромосом [11, 12]. Такие методы не позволяют обнаружить хромосомные перестройки, которые могут присутствовать на других хромосомах. В клинической практике встречались случаи, при которых после проведения таргетного НИПС были пропущены делеции как отдельных участков хромосом $22 \mathrm{q} 11$ - синдром ДиДжорджа, так и целого короткого плеча $5 p$ - синдром кошачьего крика, что приводило к рождению больного ребенка.

Б

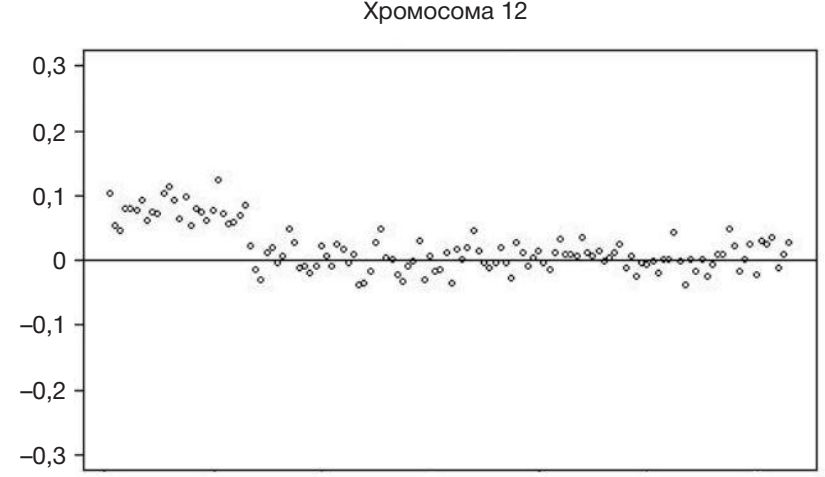

Рис. 1. Визуализация распределения ридов по длине хромосомы. По оси ординат указаны отклонения количества ридов от ресеренсных значений, формируемых для нормального генотипа. А. Распределение для хромосомы 4. Б. Распределение для хромосомы 12 


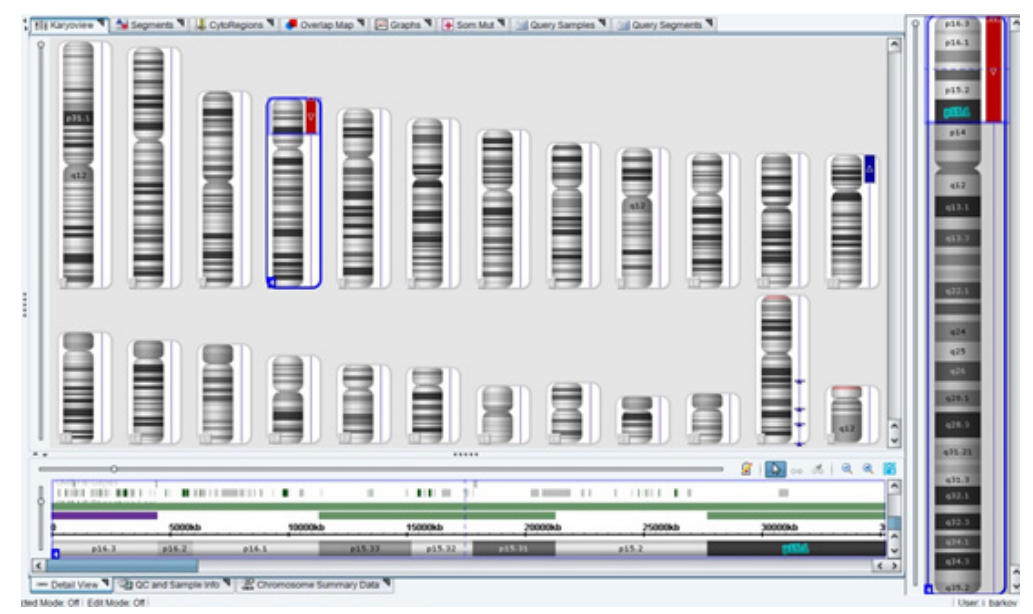

Рис. 2. Результаты молекулярного кариотипирования амниотической жидкости пациентки П. - делеция на коротком плече 4-й хромосомы

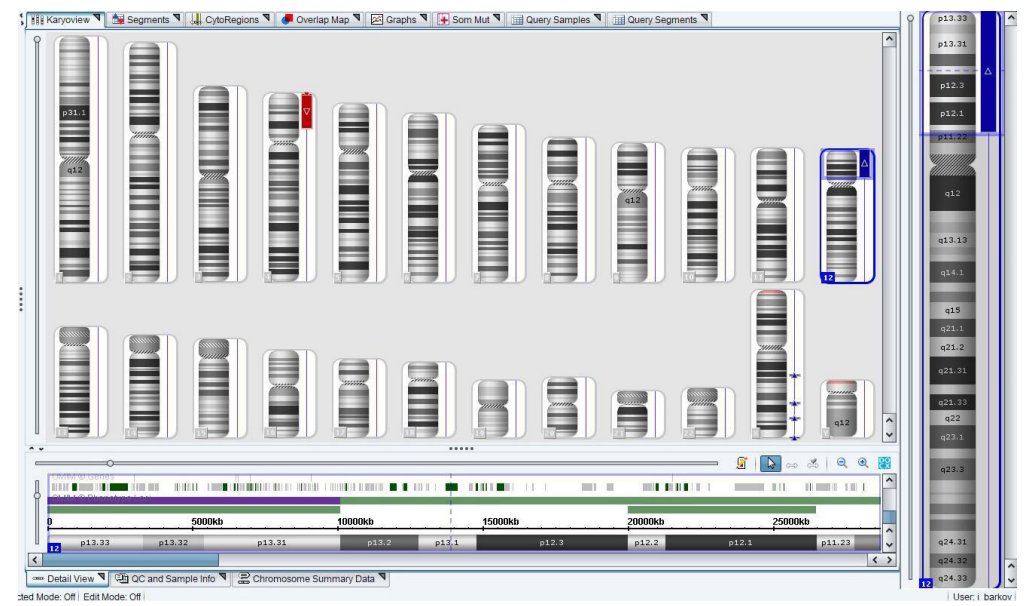

Рис. 3. Результаты молекулярного кариотипирования амниотической жидкости пациентки П. — дупликация на коротком плече 12-й хромосомы

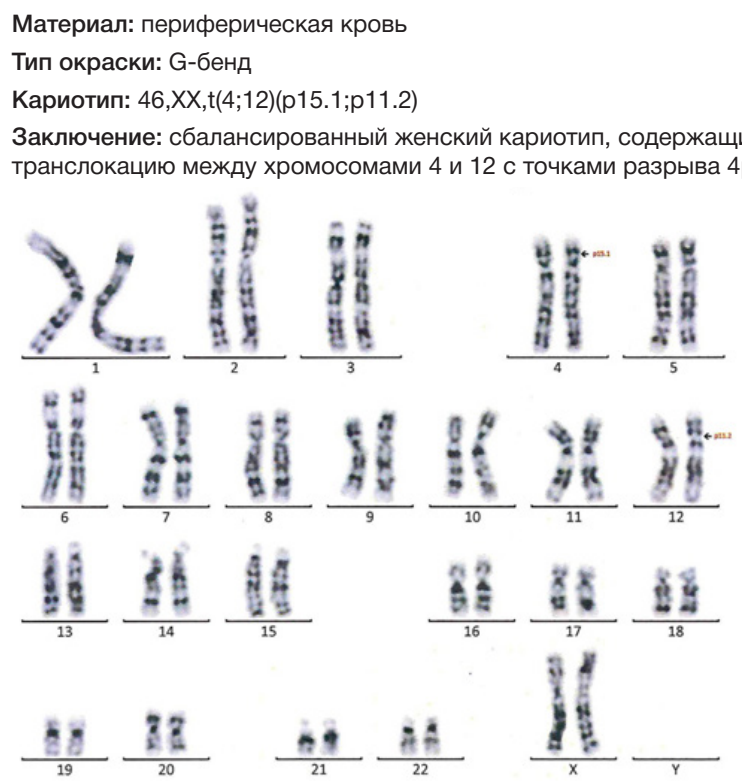

Рис. 4. Результаты кариотипирования пациентки П.

\section{ВЫВОДЫ}

По результатам данного клинического случая можно сделать выводы как частного, так и общего характера. В связи с высоким риском хромосомных нарушений при следующей беременности пациентке П. и ее супругу рекомендовано проведение преимплантационной генетической диагностики. При проведении НИПС полногеномный подход, в отличие от таргетного, имеет преимущества, так как его использование не приводит к потере данных по клинически важным участкам генома. А при проведении полногеномного НИПС необходимо проводить анализ всех хромосом. 


\section{Литература}

1. Ehrich M, Deciu C, Zwiefelhofer T, Tynan JA, Cagasan L, Tim R, et al. Noninvasive detection of fetal trisomy 21 by sequencing of DNA in maternal blood: a study in a clinical setting. American journal of obstetrics and gynecology. 2011; 204 (3): 205-e1.

2. Wald NJ, Hackshaw AK. Combining ultrasound and biochemistry in first-trimester screening for Down's syndrome. Prenatal diagnosis. 1997; 17 (9): 821-9.

3. Zhang H, Gao Y, Jiang F, Fu M, Yuan Y, Guo Y, et al. Non-invasive prenatal testing for trisomies 21, 18 and 13: Clinical experience from 146958 pregnancies. Ultrasound Obstet. Gynecol. 2015; 45 (5): 530-8.

4. Hartwig TS, Ambye L, Sørensen S, Jørgensen FS. Discordant non-invasive prenatal testing (NIPT) - a systematic review. Prenat Diagn. 2017; 37 (6): 527-39.

5. Canick JA, Palomaki GE, Kloza EM, Lambert-Messerlian GM, Haddow JE. The impact of maternal plasma DNA fetal fraction on next generation sequencing tests for common fetal aneuploidies. Prenat Diagn. 2013; 33 (7): 667-74.

6. Сухих Г. Т., Каретникова Н. А., Баранова Е. Е., Шубина Е. С., Коростин Д. О., Екимов А. Н. и др. Неинвазивная пренатальная диагностика анеуплоидий методом высокопроизводительного секвенирования (NGS) в группе женщин высокого риска. Акушерство и гинекология. 2015; (4): 5-10.

\section{References}

1. Ehrich M, Deciu C, Zwiefelhofer T, Tynan JA, Cagasan L, Tim R, et al. Noninvasive detection of fetal trisomy 21 by sequencing of DNA in maternal blood: a study in a clinical setting. American journal of obstetrics and gynecology. 2011; 204 (3): 205-e1.

2. Wald NJ, Hackshaw AK. Combining ultrasound and biochemistry in first-trimester screening for Down's syndrome. Prenatal diagnosis. 1997; 17 (9): 821-9.

3. Zhang H, Gao Y, Jiang F, Fu M, Yuan Y, Guo Y, et al. Non-invasive prenatal testing for trisomies 21, 18 and 13: Clinical experience from 146958 pregnancies. Ultrasound Obstet. Gynecol. 2015; 45 (5): 530-8.

4. Hartwig TS, Ambye L, Sørensen S, Jørgensen FS. Discordant non-invasive prenatal testing (NIPT) - a systematic review. Prenat Diagn. 2017; 37 (6): 527-39.

5. Canick JA, Palomaki GE, Kloza EM, Lambert-Messerlian GM, Haddow JE. The impact of maternal plasma DNA fetal fraction on next generation sequencing tests for common fetal aneuploidies. Prenat Diagn. 2013; 33 (7): 667-74.

6. Sukhikh GT, Karetnikova NA, Baranova EE, Shubina E, Korostin DO, Ekimov A, et al. Noninvasive prenatal diagnosis of aneuploidies by next- generation sequencing (ngs) in a group of high-risk women. Obstetrics and Gynecology. 2015; (4): 5-10.
7. Неинвазивный пренатальный ДНК-скрининг анеуплоидий плода по крови матери методом высокопроизводительного секвенирования. Клинические рекомендации. Акушерство и гинекология. 2016; (6): 1-22.

8. Lo YM, Chan KC, Sun H, Chen EZ, Jiang P, Lun FM, et al. Maternal plasma DNA sequencing reveals the genome-wide genetic and mutational profile of the fetus. Sci Transl Med. 2010; 2 (61): 61-91.

9. Fiorentino F, Bono S, Pizzuti F, Mariano M, Polverari A, Duca S, et al. The importance of determining the limit of detection of non invasive prenatal testing methods. Prenat Diagn. 2016; 36 (4): 304-11.

10. Juneau K, Bogard PE, Huang S, Mohseni M, Wang ET, Ryvkin P, et al. Microarray-Based Cell-Free DNA Analysis Improves Noninvasive Prenatal Testing. Fetal Diagn Ther. 2014; 36 (4): 282-6.

11. Wang J-C, Sahoo T, Schonberg S, Kopita K, Ross L, Patek K, et al. Discordant noninvasive prenatal testing and cytogenetic results: a study of 109 consecutive cases. Genet Med. 2015; 17 (3): 234-6.

12. Ma J, Cram DS, Zhang J, Shang L, Yang H, Pan H. Birth of a child with trisomy 9 mosaicism syndrome associated with paternal isodisomy 9: case of a positive noninvasive prenatal test result unconfirmed by invasive prenatal diagnosis. Mol Cytogenet. 2015; (8): 44.

7. Noninvasive prenatal DNA-scrining fetal aneuploidy in maternal blood by next-generation sequencing (ngs) method. Clinical recommendation. Obstetrics and Gynecology. 2016; (6): 1-22.

8. Lo YM, Chan KC, Sun H, Chen EZ, Jiang P, Lun FM, et al. Maternal plasma DNA sequencing reveals the genome-wide genetic and mutational profile of the fetus. Sci Transl Med. 2010; 2 (61): 61-91.

9. Fiorentino F, Bono S, Pizzuti F, Mariano M, Polverari A, Duca S, et al. The importance of determining the limit of detection of non invasive prenatal testing methods. Prenat Diagn. 2016; 36 (4): 304-11.

10. Juneau K, Bogard PE, Huang S, Mohseni M, Wang ET, Rykkin P, et al. Microarray-Based Cell-Free DNA Analysis Improves Noninvasive Prenatal Testing. Fetal Diagn Ther. 2014; 36 (4): 282-6.

11. Wang J-C, Sahoo T, Schonberg S, Kopita K, Ross L, Patek K, et al. Discordant noninvasive prenatal testing and cytogenetic results: a study of 109 consecutive cases. Genet Med. 2015; 17 (3): 234-6.

12. Ma J, Cram DS, Zhang J, Shang L, Yang H, Pan H. Birth of a child with trisomy 9 mosaicism syndrome associated with paternal isodisomy 9: case of a positive noninvasive prenatal test result unconfirmed by invasive prenatal diagnosis. Mol Cytogenet. 2015; (8): 44. 